\title{
Relationship between preparation to take off and ground reaction force characteristics in male long jumpers
}

\section{*Essam Ghareb, "Osama Elshaer, "*Moamen Abd Elgawad}

* Lecture Doctor, Department of Athletics Training, Faculty of physical education for men, Alexandria University

** Assistant Lecture, Department of Athletics Training, Faculty of physical education for men, Alexandria University

Introduction

Rational and efficient processes of learning and performance of long jump in training and competition should be based on a detailed biomechanical analysis. Coaches cannot perceive all of the important elements of technique by visual perception (observation), therefore the need for kinematic, dynamic analysis of long jump technique has become usual for athletic practice [12]

A long jump consists of four phases-the approach (or run-up), the takeoff, the flight and the landing. The requirements for success in the event are generally regarded as consisting of (a) an approach that brings the athlete to the board with a large horizontal velocity and with the dominant foot appropriately placed for takeoff, (b)a takeoff in which vertical velocity is acquired with little loss in horizontal velocity, (c)a flight that permits the athlete to assume the optimum position for landing, and (d)a landing in which the athlete passes forward of the mark made by the feet without sitting back or otherwise decreasing the distance of the jump.[9]

During the final strides of the approach in the long jump, the athlete aims to: (a) Adjusts the lengths of the remaining strides to correct for previous errors in striding (b) Adjusts the position of the body in preparation for takeoff; and (c) Attempts to increase horizontal velocity to arrive at the board with the maximum that can be controlled during the takeoff. The adjustments in body position in preparation for takeoff serve to bring the athlete to the takeoff board in a position that facilitates the development of vertical velocity during the takeoff[6]

The purpose of the takeoff phase is to obtain vertical velocity while retaining is as much horizontal velocity as possible. As the athlete's foot lands at the end of the last stride of the run-up; the hip, knee and ankle joints flex a little to cushion the shock of the impact and to position of the leg for the vigorous extension to follows moments later [7] However, to make best use of this run- 
up velocity the athlete must generate appropriate forces at take-off so as to launch their body at the optimum takeoff velocity and take-off angle[15]

The take-off leg is an important element in long jumping, as it transfers the large contact force that gives the necessary upward momentum to the jumper's. During the takeoff, the athlete is subject to ground reaction forces which tend to angularly accelerate him about the transverse axis through his center of gravity. For most of the takeoff, the horizontal force acts to angularly accelerate him in a forwardsomersaulting (or clockwise) direction. The vertical force initially acts to angularly accelerate him in a backwardsomersaulting (or counter-clockwise) direction and then, once his center of gravity has passed forward of the center of pressure, in a forward-somersaulting (or clockwise) direction. The resultant moment acting on the athlete is first directed backward or counter-clockwise (as a result of the dominant influence of the vertical force acting in front of the center of gravity); then forward or clockwise (as both horizontal and vertical forces act [10]

Perhaps the most critical characteristic of long jumping technique is the placement of the foot well in front of the body at touch-down. This is facilitated by the low position of the center of mass. If the leg was not placed well in front of the center of mass, then the leg would have to be flexed considerably at the knee, providing a weak position to absorb the considerable ground reaction forces, there are several mechanisms which may operate as a result of this.[8]

The muscles of the leg are activated prior to

touch-down and thus provide a strong resistance to flexion at the major joints. This 'stiff' leg enables the center of mass to ride over the base, providing an upward vertical velocity of the center of mass at the moment when the extensor muscles begin their concentric contractions at maximum knee flexion. This might be regarded as a purely mechanical mechanism producing upward velocity[2]

The generation of vertical velocity to obtain vertical lifts while maintaining horizontal velocity is a critical element in long jumps for maximum distance. For example[7], Hay and colleagues have described selected characteristics of the techniques used by elite long jumpers during the transition from approach to takeoff in the long jump and identified the characteristics that were significantly related to the distance of the jump [8] During the take-off the athlete experiences a ground reaction force (GRF) that tends to change the speed and direction of the athlete's COM. The horizontal force during the take-off is Predominantly a backwards braking force, and only for a very short time at the end of the takeoff, Because the braking impulse is much greater than the propulsive impulse, the athlete's forward horizontal velocity is reduced during the take-off (by about 1-3 m/s). 
The vertical GRF exerted on the athlete produces the athlete's vertical take-off velocity. The vertical force initially acts to reverse the downward velocity possessed by the athlete at touchdown, and then accelerates the athlete upwards. Both the horizontal and vertical components of the GRF display a sharp impact peak at touchdown when the takeoff leg strikes the ground and is rapidly reduced to near zero velocity.[11]
Previous studies in long jump have been focused on kinematical analysis of takeoff techniques $[3,5,6,7,17]$ ground reaction forces during takeoff $[11,14]$,but no previous studies focus on the relationship between ground reaction forces and preparation to takeoff. So the main aim of the present study is to examine the relationship between ground reaction forces characteristics and preparation to take off parameters.

\section{Methods}

\section{Subjects:}

Six national level male long jumpers (age: $22.30 \pm 2.20$, height:1.84 \pm 0.027 , weight :73.5 \pm 6.65 , personal best:6.54 \pm 0.42 ) were participated in the current study ,aftar an appropriate warm up every jumper had three trails. The best trial of each of the six subjects was analyzed in obtaining kinematic and kinetic data. Data were obtained only when the performer was in contact with

the force platform. The study was conducted in an outdoor track in the faculty of physical education, Alexandria University .The study procedures began when all jumpers declared themselves ready to begin, the participants performed without spikes on their shoes in order to protect their feet from the shock of hitting a hard metal take off plate located beneath the covering.

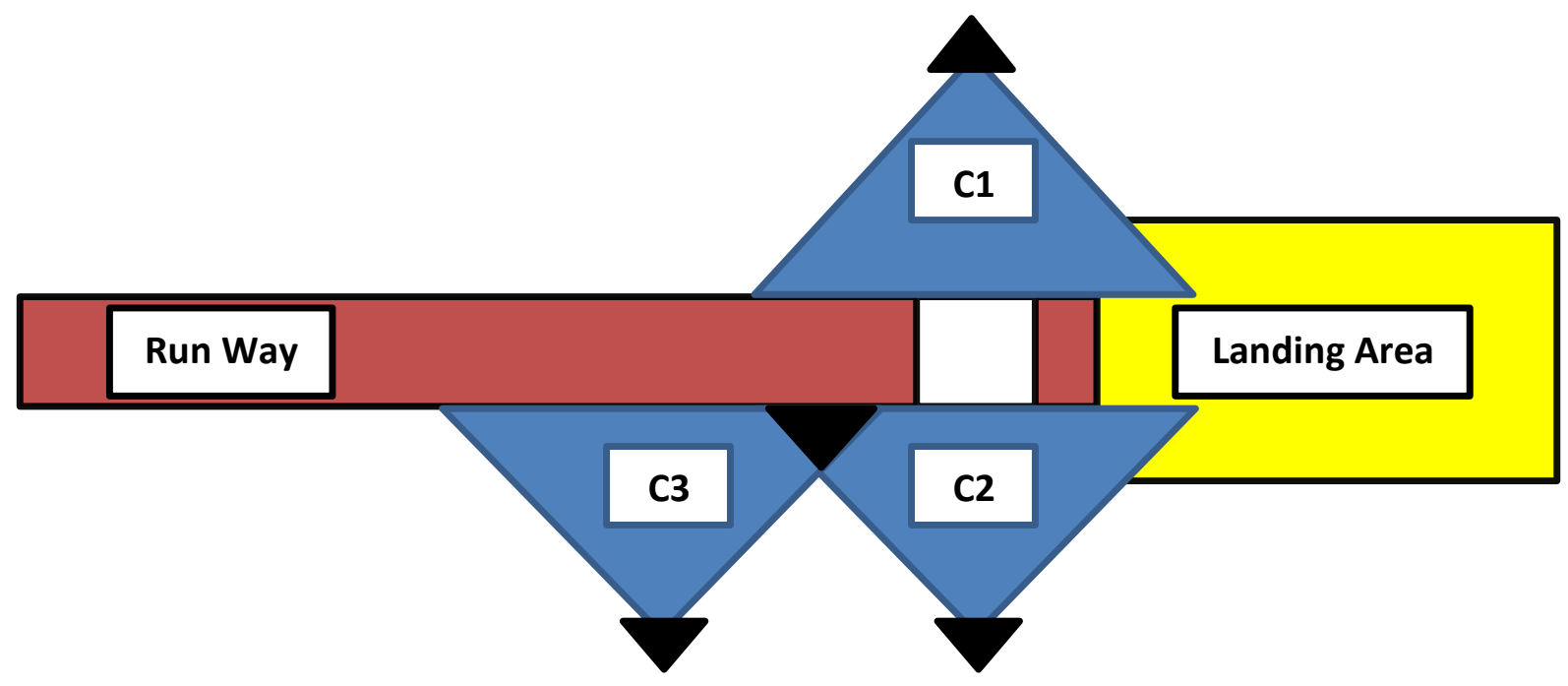


Figure 1: Cameras, force platform positions used for kinematic and kinetic data collection

\section{Kinematic data collection}

To determine the kinematics of each trail, several anatomical landmarks were identified with $2 \mathrm{~cm}$ markers: ankle; knee; hip; wrist; elbow; shoulder; top of the head; center of the ear; center of the neck; tip of the little finger; and fifth metatarsal joint. Three video cameras ( Panasonic DCRSR 58 ) $50 \mathrm{~Hz}$ were used in the current study to collect

\section{Kinetic data collection:}

One force platform (Bertec4060-10, Frequency $1000(\mathrm{~Hz}) ;[0.90 \mathrm{~m} \times 0.60 \mathrm{~m}$ $x 0.10 \mathrm{~m}$ ) was placed in a customized housing in the takeoff area to collect kinetic data;The force data were filtered using a low pass Butterworth filter and a cut-off frequency of $300 \mathrm{~Hz}$ based on frequency analysis of the force plate signal in its above-mentioned set-up. Several parameters were then calculated for the vertical (Fz) and horizontal (Fy) ground reaction force,

kinematic data, two cameras were placed perpendicular to the force platform with a field of view $5 \mathrm{~m}$ to collect kinematic data of the takeoff leg from each side, the third camera was placed perpendicular to the end of run way covering $8 \mathrm{~m}$ before the force platform . normalized to individual body mass $(\mathrm{kg})$ for all subjects. Impact peak force (Fz1), loading peak force (Fz2), total impulse (integral from touch-down to take-off)), rate of force loading RFD (the slope of the line from Fz minimum to Fz2) (Figure 1), and peak braking force (Fy1), peak propulsive force (Fy2).for Statistical analysis to Means, standard deviations, and Simple correlation coefficient were used. 


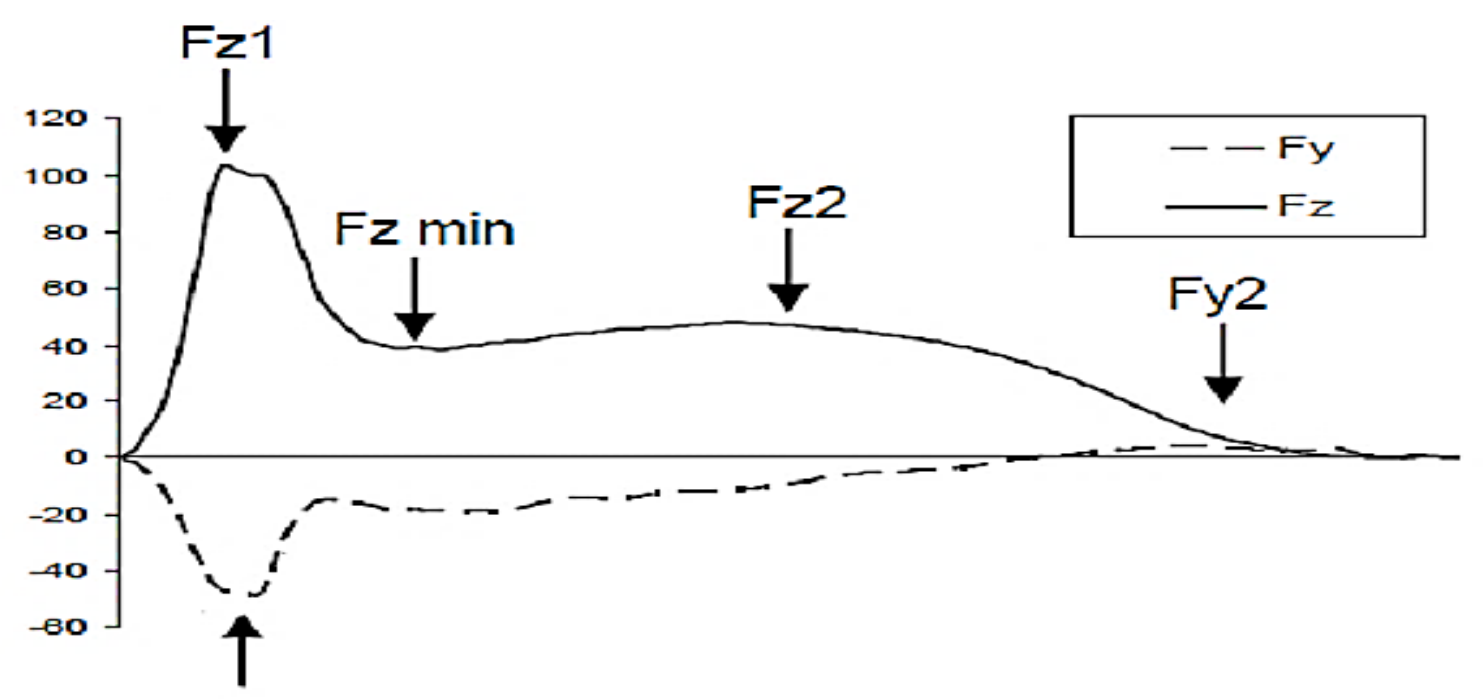

Fy1

Figure 2.Ground reaction forces characteristics for research subjects, the forces are normalized in the $\mathrm{X}$ axis from touchdown to takeoff.

\section{$\underline{\text { Results }}$}

Table1. Means (SD) for kinematic data of last two steps before take off

\begin{tabular}{|c|c|c|}
\hline & Mean & SD \\
\hline \multicolumn{3}{|l|}{$\overline{P \text { Penultimate Step }}$} \\
\hline Step length $(\mathrm{m})$ & 2.28 & 0.162 \\
\hline Step time (s) & 0.25 & 0.021 \\
\hline Step velocity $(\mathrm{m} / \mathrm{s})$ & 9.03 & 0.386 \\
\hline CM height & 0.96 & 0.025 \\
\hline \multicolumn{3}{|l|}{ Final Step } \\
\hline Step length (m) & 1.80 & 0.157 \\
\hline Step time (s) & 0.21 & 0.021 \\
\hline Step velocity $(\mathrm{m} / \mathrm{s})$ & 8.48 & 0.599 \\
\hline CM height (m) & 0.91 & 0.015 \\
\hline
\end{tabular}

Table2 . Means (SD) for kinematic data of takeoff step 


\begin{tabular}{l|l|l}
\hline \hline CM horizontal velocity $(\mathrm{m} / \mathrm{s})$ & 8.25 & 0.304 \\
\hline CM vertical velocity $(\mathrm{m} / \mathrm{s})$ & 2.61 & 0.226 \\
\hline $\begin{array}{l}\text { CM height at touch } \\
\text { down }(\mathrm{m}\end{array}$ & 0.92 & 0.021 \\
\hline $\begin{array}{l}\text { CM height at } \\
\text { amortization }(\mathrm{m})\end{array}$ & 0.93 & 0.020 \\
\hline CM height at takeoff $(\mathrm{m}$ & 1.13 & 0.030 \\
\hline Official distance $(\mathrm{m})$ & 6.33 & 0.105 \\
\hline \hline
\end{tabular}

Table 3. Means (SD) for ground reaction force characteristics during take off

\begin{tabular}{l|l|l}
\hline \hline & Mean & SD \\
\hline \hline Fz1 (N/kg) & 81.82 & 7.786 \\
\hline Fz2 (N/kg) & 43.71 & 3.765 \\
\hline Fz minimum (N/kg) & 33.56 & 6.530 \\
\hline Total impulse (N.s/kg) & 3.17 & 0.870 \\
\hline $\begin{array}{l}\text { Rate of force } \\
\text { development(N/kg.s) }\end{array}$ & 1815.39 & 296.505 \\
\hline Fy1 (N/kg) & -30.55 & -4.052 \\
\hline Fy2 (N/kg) & 5.06 & 1.017 \\
\hline Foot contact duration (s) & 0.14 & 0.01 \\
\hline \hline
\end{tabular}

Table 4. Correlation coefficient between ground reaction force characteristics and kinematic data of last two steps before take off

\begin{tabular}{|c|c|c|c|c|c|c|}
\hline & $\begin{array}{l}\text { Fz1 } \\
(\mathrm{N} / \mathrm{kg})\end{array}$ & $\begin{array}{l}\text { Fz2 } \\
(\mathrm{N} / \mathrm{kg})\end{array}$ & $\begin{array}{l}\text { Fz } \\
\text { minimum } \\
(\mathrm{N} / \mathrm{kg})\end{array}$ & $\begin{array}{l}\text { RFD } \\
\text { (N/kg.s) }\end{array}$ & $\begin{array}{l}\text { Fy1 } \\
\text { (N/kg) }\end{array}$ & $\begin{array}{l}\text { Fy2 } \\
\text { (N/kg) }\end{array}$ \\
\hline \multicolumn{7}{|c|}{ Penultimate Step } \\
\hline $\begin{array}{l}\text { Step length } \\
\text { (m) }\end{array}$ & $0.742^{*}$ & $0.705^{*}$ & 0.554 & $0.950^{*}$ & 0.441 & -0.586 \\
\hline Step time (s) & $0.846^{*}$ & 0.412 & 0.298 & $0.892^{*}$ & $0.732^{*}$ & -0.623 \\
\hline $\begin{array}{l}\text { Step velocity } \\
(\mathrm{m} / \mathrm{s})\end{array}$ & -0.515 & 0.197 & 0.179 & -0.325 & $0.708^{*}$ & 0.312 \\
\hline CM height & 0.317 & -0.503 & 0.011 & 0.144 & 0.448 & 0.216 \\
\hline \multicolumn{7}{|l|}{ Final Step } \\
\hline $\begin{array}{l}\text { Step length } \\
\text { (m) }\end{array}$ & $0.753^{*}$ & 0.142 & -0.005 & -0.326 & $0.888^{*}$ & 0.238 \\
\hline Step time (s) & -0.550 & 0.005 & -0.121 & -0.116 & -0.561 & 0.071 \\
\hline Step velocity & -0.235 & 0.163 & 0.171 & -0.290 & -0.382 & 0.243 \\
\hline
\end{tabular}




\begin{tabular}{l|l|l|l|l|l|l}
\hline \hline$(\mathrm{m} / \mathrm{s})$ & & & & & & \\
\hline $\begin{array}{l}\mathrm{CM} \text { height } \\
(\mathrm{m})\end{array}$ & $0.349-$ & $0.550-$ & 0.122 & $0.210-$ & $0.258-$ & 0.655 \\
\hline \hline
\end{tabular}

Table 5. Correlation coefficient between ground reaction force characteristics and kinematic data of takeoff phase

\begin{tabular}{l|l|l|l|l|l}
\hline \hline & $\begin{array}{l}\mathrm{Fz1} \\
(\mathrm{N} / \mathrm{kg})\end{array}$ & $\begin{array}{l}\mathrm{Fz2} \\
(\mathrm{N} / \mathrm{kg})\end{array}$ & $\begin{array}{l}\text { Fz minimum } \\
(\mathrm{N} / \mathrm{kg})\end{array}$ & $\begin{array}{l}\text { Fy1 } \\
(\mathrm{N} / \mathrm{kg})\end{array}$ & $\begin{array}{l}\text { Fy2 } \\
(\mathrm{N} / \mathrm{kg})\end{array}$ \\
\hline \hline CM horizontal velocity $(\mathrm{m} / \mathrm{s})$ & -0.023 & -0.645 & 0.069 & 0.243 & 0.519 \\
\hline CM vertical velocity(m/s) & -0.461 & $0.857^{*}$ & -0.303 & -0.123 & $0.772^{*}$ \\
\hline $\begin{array}{l}\text { CM height at touch } \\
\text { down }(\mathrm{m})\end{array}$ & 0.363 & 0.405 & -0.184 & -0.140 & $0.696^{*}$ \\
\hline $\begin{array}{l}\text { CM height at } \\
\text { amortization(m) }\end{array}$ & 0.215 & 0.470 & -0.104 & -0.166 & -0.664 \\
\hline CM height at takeoff(m) & 0.593 & $0.774^{*}$ & 0.435 & 0.373 & $0.700^{*}$ \\
\hline \multicolumn{1}{c}{ Contact Time(s) } & 0.626 & 0.470 & $0.789^{*}$ & $0.710^{*}$ & -0.188 \\
\hline \hline
\end{tabular}
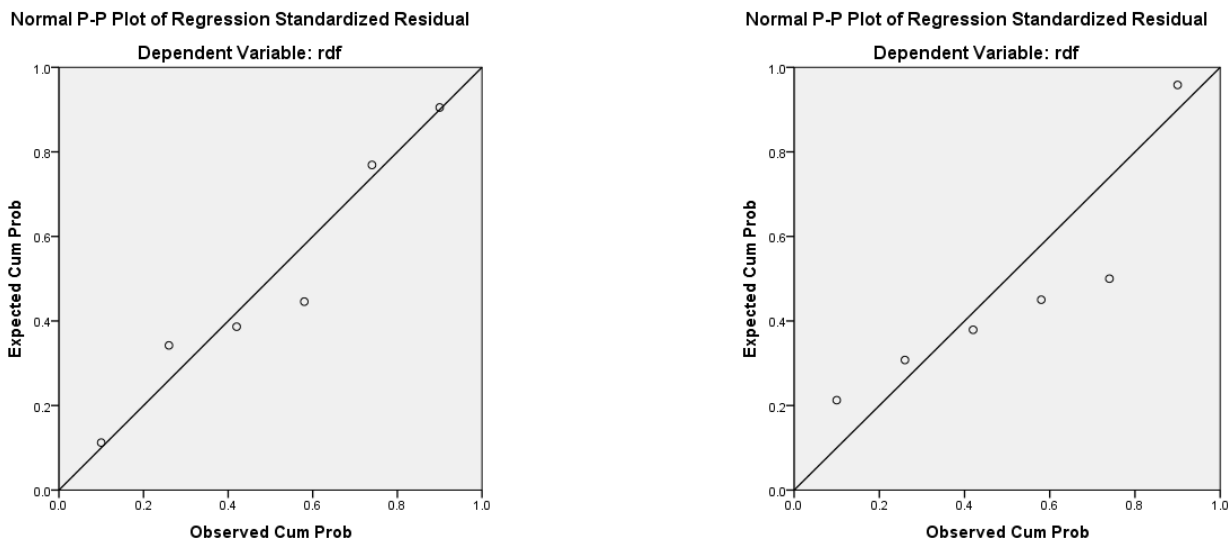

Figure 3 : correlation coefficient between penultimate step length and RDF Figure 4 : shows correlation coefficient between takeoff time and RDF

\section{Discussion}

The main aim of the present study to examine the relationship between ground reaction force characteristics and preparation to take off, table 1 shows changes of step length ,CM height during the last two steps of approach ;step length changes about $0.61 \mathrm{~cm} \mathrm{(25 \% )}$ this results agreed with previous studies[4,5] suggested that During the final strides of the approach in the long jump, the athlete: (a) adjusts the lengths of the remaining strides to 
correct for previous errors in striding [6]. The adjustments in body position in preparation for takeoff serve to bring the athlete to the takeoff board in a position that facilitates the development of vertical velocity during the takeoff , $\mathrm{CM}$ height decreased about $5 \mathrm{~cm}(5.2 \%)$ this value was similar to the values of previous studies [5].also table 2 shows a continues decrease CM height from braking to amortization during takeoff action ,Nixdorf and Bruggeman (1983)that there was a radical lowering to $\mathrm{CM}$ height (equal to $7 \%$ of the approach height) between takeoff into the second-last stride and the following touchdown; and (d) a continued lowering until at touchdown on the board the $\mathrm{CM}$ was 10 per cent (or $11 \mathrm{~cm}$ ) lower than the approach height. [14.] On the basis of these findings they concluded. 'With the greatest reservation', that 'the degree of lowering of the center of gravity is an indicator of technique'. Also table 1 shows a decrease of step velocity from Penultimate Step to final step about $11.57 \%$, the decrease of horizontal velocity in the final step is due to the decrease of step length to facilitates the development of vertical velocity during the takeoff.[6]

Table2 shows the values of $\mathrm{CM}$ horizontal and vertical velocity during takeoff ( 8.475 - $2.605 \mathrm{~m} / \mathrm{s}$ respectively) those values were similar to previous studies [4,5] $8.12-2.92 \mathrm{~m} / \mathrm{s}$ for horizontal and vertical velocity respectively, according to those results; jumpers loss about $2.59 \%$ of their horizontal velocity during the transition from approach to take off , Alexander (1990) demonstrated that vertical velocity is a determine factor in long jump ,the greatest gain in vertical velocity is during the compression phase which is associated with a loss of horizontal velocity[3]. The low angle of take-off in long jumping $\left(18^{\circ}-24^{\circ}\right)$ means that any change in vertical velocity has a greater influence on jump distance than an equivalent change of horizontal velocity, and so the mechanisms leading to a gain in vertical velocity and loss of horizontal velocity are of particular interest in long jumping. This led us to propose that the gain in vertical velocity was primarily achieved by the action of the body moving or pivoting over the fixed foot of the touchdown leg and being forced upwards, generating vertical velocity at the expense of horizontal velocity[17]

Values of ground reaction force characteristics during takeoff (table 3) were similar of previous studies $[4,12,18]$ for able bodies' athletes during long jump or pole vaulting. Table 4 shows correlation coefficient between ground reaction force characteristics and preparation to takeoff. A significant positive linear relationship was found between impact peak force (Fz1), and both step length and step time $(r=$ $0.742,0.846$ respectively), and a significant positive linear relationship was found between loading peak force (Fz2) and step length $(r=0.705)$ during Penultimate Step; that is due to the increase in step length $(0.61 \mathrm{~cm})$; 
running or sprinting step time consists of contact time and flight time, the increase step length requires an increase in force production which result of an increase in contact time, as step length increase both impact, loading peak force increase as a result of the impact of jumper's foot with the ground, that reflects the relationship between Fz1, Fz2 and step length and time during both Penultimate and final Step.

Also in table 4 a significant positive linear relationship was found between RDF and both step length and step time during preparation to take off ,this result confirms the importance of the preparation phase to takeoff; as the jumper adjustments his Penultimate Step length in preparation to takeoff that obviously serves him to bring his foot in a position that facilitates the development of vertical force and velocity at takeoff. A significant positive linear relationship was found between peak braking force and both step time and velocity during Penultimate Step and also a significant positive linear relationship was found between peak braking force and step length during final step before takeoff, those results were compatible with the results of previous studies (Nicholas P. Linthorne et al 2011) which demonstrated that the athlete's horizontal braking impulse increased with increasing run-up velocity, but not so much as to negate the increase in run-up velocity so leg muscular stiffness plays an important rule to reduce the loss of horizontal velocity and Facilitate the pivot action of the body over the foot;as running speed increase the braking force also increase during final two steps because the jumper tends to adjust his body position to prepare to take off by extend his takeoff leg and plants his foot ahead of the center of mass which cause a decrease in horizontal velocity (as seen in table 2) as a result of large braking force.[15]

Table 5 shows correlation coefficient between ground reaction force characteristics and kinematic data of takeoff phase. A significant positive linear relationship was found between loading peak force (Fz2) and both CM vertical velocity and height during takeoff, also a positive linear relationship was found between RFD and $\mathrm{CM}$ height at touch down and $\mathrm{CM}$ height at takeoff; this result agreed with the previous studies showed that there is a positive relationship between Fz2 and flight distance in long jump[10]. This means that as Fz2 increases flight distance increase as a result of the large amount of vertical velocity generated during takeoff. Also during takeoff the greatest gain in vertical velocity is during the compression phase (defined as the period from touch-down to when the knee reaches its maximum angle of flexion) followed by a maximum flexion in lower limb joints in takeoff direction which cause an increase in both $\mathrm{CM}$ height and vertical velocity[17] Also a significant negative relationship was found between RFD and CM 
vertical velocity, This result was interesting; Lee Nolan, and Kjartan Halvorsen (2007) demonstrated that a consequence of applying the vertical loading force over a longer duration is that the rate at which the force is developed is small [12].So longer ground contact time during takeoff is necessary to develop a large amount of vertical force which is needed to maximize the magnitude of vertical velocity.
Also a significant positive relationship was found between peak propulsive force (Fy2) and CM vertical velocity, CM height at touch down and $\mathrm{CM}$ height at takeoff, those results are compatible with the results of previous studies $[12,18]$ During the propulsive part of the take-off phase the jumper tend to maximize peak propulsive force to effectively producing vertical velocity by the continuous extending of leg joints ( hip-knee-ankle) which cause an increase in $\mathrm{CM}$ height and vertical velocity

\section{$\underline{\text { Conclusion }}$}

Although the importance of takeoff phase for generating the appropriate force in long jump, the preparation to takeoff phase also plays an important role at the same moment the adjustment of final steps obviously serves him to bring his foot in a position that facilitates the development of vertical force and velocity at takeoff his final steps before takeoff to reach the optimum position for force production. Longer ground contact time during takeoff is necessary to develop a large amount of vertical force which is needed to maximize the magnitude of vertical velocity. As a consequence of applying the vertical loading force over a longer duration is that the rate at which the force is developed is small. So training programs should include technical exercises to optimize the preparation phase of takeoff, also coaches should design special exercises to maximize leg stiffness during takeoff. 



\section{$\underline{\text { References }}$}

1- A. Seyfarth, A. Friedrichs, V. Wank, R. Blickhan (1999)

Dynamics of the long jump Journal of Biomechanics $321259\} 1267$

2- A. LEES, N. FOWLER and D. DERBY

A biomechanical analysis of the last stride, touchdown and take-off characteristics of the women's long jump, Journal of Sports Sciences, 1993, 11, 303-314

3- Alexander, R.McN. (1990) Optimum take-off techniques for high and long jumps. Philosophical Transactions of the Royal Society of London. Series B, 329, 3-10

4- Chen-Fu Huang, ChungShou Kao (2007)

BIOMECHANICAL DIFFERENCES BETWEEN JUMPERS AND SPRINTERS ON LONG JUMP PERFORMANCE, XXI ISB Congress, Poster Sessions, Thursday 5 July 2007

5- Emel Çetin, Özgür Özdemir, Yeliz Özdöl ( 2014 )

Kinematic analysis last four stride lengths of two different long jump performance Social and Behavioral Sciences $1162747-2751$

6- Hay, J. G. and Nohara. H. (1990)

The techniques used by elite long jumpers in preparation for takeoff. J. Biomechanics 23. 229-239.

7- Hay JG, Miller JA. (1985) Techniques used in the transition from approach to takeoff in the long jump. Int J Sport Biomech;1:174-84.

8- JAMES G. HAY (1993)

CITIUS, ALTIUS, LONGIUS (FASTER, HIGHER, LONGER):

THE BIOMECHANICS OF JUMPING FOR

DISTANCE, J, Biomechmics Vol. 26, Suppl.1, pp 7-21, 1993

9- JAMES G. HAY, JOHN A. THE TECHNIQUES OF ELITE MALE LONG MILLER and RON W. CANTERNA(1985)

9- J. F. BEDI and J. M. COOPER (1977)

TAKE OFF IN THE LONG JUMP-ANGULAR MOMENTUM CONSIDERATIONS .I. Bwwchantcr. 1977. Vol. IO. pp. 541-548 
10 - Lee Nolana,b and Kjartan Halvorsena(2007)

11 -Linthorne, N.P. (2008).

12 - Milan Matić, Vladimir Mrdaković, Nenad Janković1, Duško llić, Đorđe Stefanović, Saša Kostić (2012)

13 - Nixdorf, E. \& Brüggemann, P. (1983).

14 - Nicholas P. Linthorne,Craig Baker, Montell M.M. Douglas, Gary A. Hill and Richard G. Webster:

15 - Nicholas P Linthornea, Maurice S Guzmanb \& Lisa A Bridgettc (2007)

16 - Philip Graham-Smith a \& Adrian Lees b(2005)

17 - Plessa Efstathia, Boudolos Konstantinos:

18 - Vassilios Panoutsakopoulos, Georgios I. Papaiakovou, Fotios S. Katsikas, Iraklis A. Kollias (2010)
GROUND REACTION FORCES DURING LONG JUMP TAKE-OFF FOR TRANSTIBIAL AMPUTEES, 25 International Symposium on Biomechanics in Sports)

Biomechanics of the long jump. In Y. Hong \& R. Bartlett (Eds.), Routledge Handbook of Biomechanics and Human Movement Science (pp 340-353). London: Routledge.

ACTIVE LANDING AND TAKE-OFF KINEMATICS OF THE LONG JUMP $\square$ Physical Education and Sport Vol. 10, No 3pp. $243-256$

Zur absprungvorbereitung beim weitsprung. Eine biomechanische untersuchung zum problem der körperschwerpunktsenkung. Die Lehre der Leichtathletik 1539-1541

TAKE-OFF FORCES AND IMPULSES IN THE LONG JUMP, Portuguese Journal of Sport Sciences 11 (Suppl. 3), 2011

Optimum take-off angle in the long jump Journal of Sports Sciences Volume 23, Issue 7

A three-dimensional kinematic analysis of the long jump take-off, Journal of Sports Sciences, September 2005; 23(9): $891-903$

Comparison of ground reaction forces during the take off phase of pole vault and long jump, J SPORTS MED PHYS FITNESS 2010;34:1-2

3D Biomechanical Analysis of the Preparation of the Long Jump Take-Off New Studies in Athletics 25:1; $55-68,2010$ 
